\title{
Paddy farm management practices: the case of Sungai Petani area in Malaysia
}

\begin{abstract}
Because on-farm income has played an important role in rural livelihood, it is important to comprehend the influential factors behind its productivity in order to improve farmers' income and support future agricultural developments in subgranary areas like Sungai Petani. The objective of this study is to specify the influential determinants for yield and quantity of paddy production in the subgranary area. Surveys were conducted in Sungai Petani, Kedah state. Interviews with farmers covered the individual management schemes practiced in the area as well as the sociodemographic characteristics. Yield determination and the CobbDouglas production function estimation were applied to estimate significant factors influencing the productivity and the production. The result indicates that more labor input, quantity of seeds, and technical support in the farming pratice will bring a higher yield. By the same token the size of land and labor input can directly influence the quantity of paddy production.
\end{abstract}

Keyword: Cobb-Douglas; Farm management practices; Income; Paddy; Yield determinant 